\title{
Comparison of LC and LC/MS Methods for Quantifying $N$-Glycosylation in Recombinant IgGs
}

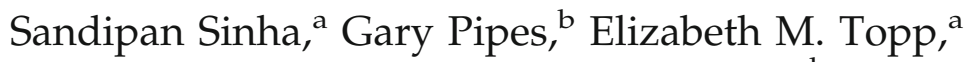 \\ Pavel V. Bondarenko, ${ }^{c}$ Michael J. Treuheit, ${ }^{\mathrm{b}}$ and Himanshu S. Gadgil ${ }^{\mathrm{b}}$ \\ ${ }^{a}$ Department of Pharmaceutical Chemistry, University of Kansas, Lawrence, Kansas, USA \\ ${ }^{\mathrm{b}}$ Department of Analytical and Formulation Sciences, Amgen Inc., Seattle, Washington, USA \\ ${ }^{c}$ Department of Formulation and Analytical Resources, Amgen Inc., Thousand Oaks, California, USA
}

\begin{abstract}
High-performance@iquid@hromatography@LC)@nd@iquid@hromatography/electrospray ionization@ime-of-flight@nass@pectrometry@LC/ESI-MS)@methods@with@arious@ample preparation@chemes@ere@omparedథror@heir@bility@o@dentify@nd@uantify@lycoforms in@wo@ifferentథroduction@ots@f@@ecombinant@onoclonal@gG1@ntibody.®gG1s@ontain a@onserved $₫$-glycosylation@ite@n@he@ragment@rystallizable $₫ F \mathrm{~F}) @$ ubunit.@ix@nethods

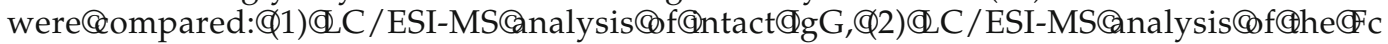

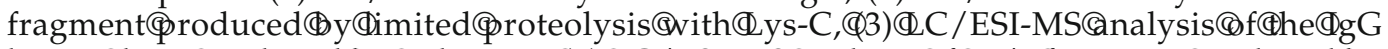

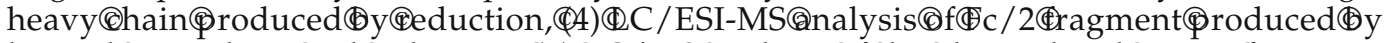
limitedథroteolysis@nd@eduction, $\$ 5)(C /$ MS@nalysis@f@he@lycosylated@ryptic@ragment (293EEQYNSTYR301)@using@xtracted@on@hromatograms, @and@6)@ormal@phase@HPLC analysis@f@-glycans@leaved@rom@heđgG@singథNGase®.@The@esults@uggest@hat@MS quantitation@based@on@theCanalysis@of@Fc /2@4)@is@accurateCand@gives@results@that@are

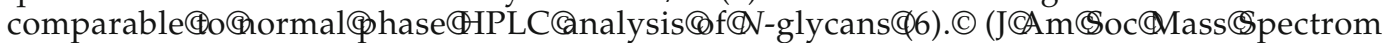

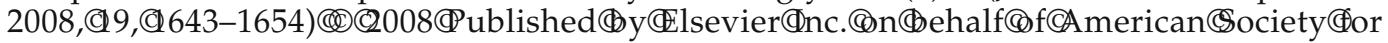
Mass@ pectrometry
\end{abstract}

G lycosylation@s@n@mportant@eterminant@f(he stability@and@biodisposition@of@protein@drugs, including@ecombinant@mmunoglobulins@IgGs). The@hallenges@nvolved@in @haracterizing@lycosylation in@recombinant@herapeutic@proteins@differ@omewhat from@hose@ssociated@ith@nalyzing@ndogenous@roteins.CStudies@f@glycosylation@inChuman@and@animal tissues@re@ften@focused@n@he@general@ariation@in glycosylationథpatterns@f@@ide@rray@fyroteins,@s@n proteomic@xperiments.@n@ontrast,@he@nalysis@erapeutic@roteins@s $₫$ ocused@n@he@omplete@haracterization@and@quantitation@of@glycosylation@in@the@protein drug@roduct.@lycosylation@n@ecombinant $₫ i$ iotherapeutic@proteins@ivaries@widely@with@the@cell@culture parameters@1, (2]@and@an@influence@fficacy, @olding, target@inding, @and@pharmacokinetic@properties $₫ 3-5]$. Both@he@ariability@nd@hysiological@ffects@f@lycosylation@make@t@mportant@o@ccurately@uantify the@arbohydrate@tructures@ound@n@iotherapeutic proteins.

Immunoglobulin@G@molecules@IgGs),@@lass@f@mmunoglobulins, Ghave@ecome@ttractive@s@herapeutic proteins@ue@o@heir@high@pecificity@nd@ong@ircula-

Address reprint requests to Dr. H. S. Gadgil, Department of Pharmaceutics, Amgen Inc., 1201 Amgen Court West, Seattle, WA 98119-3105, USA. E-mail: hgadgil@amgen.com
tionđifeథ6].@AnđgG1@molecule@s@@multi-chain,@ymmetric@protein@consisting@of@two@identical@fragment

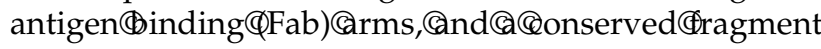

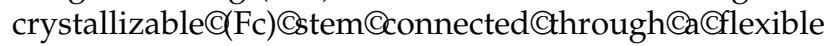
hingeథ7].đheథrab@rms@re@omposed@f@đight@hain connected@hrough@isulfide@onds@o@@ortion@f@he heavy@hain@HC).CThe@emaining@ortions@f@he@wo

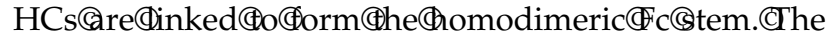
Fc@equence@s@highly@onserved@n@gG@nolecules@nd contains@@ingle@N-glycosylation@ite, $\mathbb{C A s n 2 9 7 \$ 7 ] . @ 6 l y - ~}$ cosylation@n@heథrc@efines@he@tructure@f@he@ domain@und has@een@hown@o@e@mportant@or@he

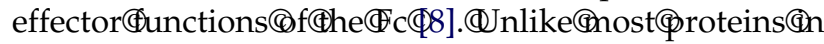
which@he@arbohydrates@re@xposed,@he@arbohydrate moiety@in@the@Fc@is@buried@between@the@two@CH2 domains\$9]@here@pace@onstraints@estrict@he@xtent of@arbohydrate@branching. CHence, (the@ypical@ylycoformథound@n@heबr@s@he@iantennary@arbohydrate structureథ8].CThe@ommon@ariability@n@lycosylation of IgG molecules is introduced by incomplete processing of the galactose and fucose residues from the biantennary oligosaccharide. In some cases, additional heterogeneity is introduced by the presence of high mannose glycoforms which are highly branched precursors of the biantennary carbohydrates [6]. While IgGs are symmetric with regard to the amino acid sequences of the light and heavy chains, glycosylation 
may be either symmetric or asymmetric [10]. Mass spectrometry can be used to identify glycoforms, as each glycoform has a specific mass determined by its composition. Recent advances in reversed-phase chromatography (rp-LC) and electrospray ionization mass spectrometry (ESI-MS) have made it possible to analyze glycoforms in samples of intact protein, as well as in protein fragments and in peptides generated after complete proteolysis with specific enzymes [11, 12]. Each of these protein sample preparation methods offers potential advantages and disadvantages for glycoform analysis by MS, a topic that has been addressed in several recent reviews [11]. Briefly, the analysis of glycosylation in intact proteins offers the advantage of minimal sample preparation and the ability to identify asymmetry in glycosylation, but the wide natural isotopic distribution of proteins may limit resolution [13]. In addition, since IgGs are highly hydrophobic, solvents such as isopropanol or $n$-propanol may be required for their reversed-phase separation. Techniques based on protein fragments or digests may offer higher resolution due to lower sample mass, but require more extensive sample preparation (e.g., digestion, reduction, alkylation) that may introduce artifacts. Furthermore, though the quantitation of glycoforms using peak intensities from deconvoluted ESI-TOF MS spectra has been reported by our group [14] and others [15], concerns remain regarding the accuracy and reproducibility of this method. An alternative approach involves chromatographic analysis of glycans released from the protein through enzymatic [16] (e.g., peptide $N$ glycosidases) or chemical (e.g., $\beta$-elimination) procedures [11]. This " $N$-glycan release assay" is relatively straightforward and well-established, but information on the site of the protein-carbohydrate bond and potential asymmetry in glycosylation of the two heavy chains is lost with this approach. Sample preparation is also more time-consuming for the $\mathrm{N}$-glycan release assay than for many of the LC/MS methods. Despite these limitations, the $\mathrm{N}$-glycan release assay is generally considered the standard for glycoform analysis in the biopharmaceutical industry.

The studies reported here compare six methods for quantifying glycosylation in two production lots of an IgG1: (1) LC/ESI-MS analysis of intact IgG ("intact IgG method"), (2) LC/ESI-MS analysis of the Fc fragment produced by limited proteolysis with Lys-C ("IgG Fc method"), (3) LC/ESI-MS analysis of the IgG heavy chain produced by reduction ("IgG HC method"), (4) LC/ESI-MS analysis of $\mathrm{FC} / 2$ fragment produced by limited proteolysis and reduction ("IgG Fc/2 method"), (5) LC/MS analysis of the glycosylated tryptic fragment (293EEQYNSTYR301) using extracted ion chromatograms ("XIC method"), and (6) normal phase HPLC analysis of the $\mathrm{N}$-glycan cleaved from the IgG using PNGase F ("N-glycan release assay"). The studies test the hypothesis that the LC/MS-based methods (i.e., methods 1-5) provide identification and quantitation of glycoforms that is equivalent to the $\mathrm{N}$-glycan release assay (i.e., method 6).

\section{Materials and Methods}

\section{Materials}

Trifluoroacetic acid (TFA), formic acid (FA) and guanidine hydrochloride $(\mathrm{GdnHCl})$ were obtained from Pierce (Rockford, IL). Tris(2-carboxyethyl) phosphine hydrochloride (TCEP) and iodoacetamide (IAM) were obtained from Sigma (St. Louis, MO). HPLC grade water and acetonitrile $(\mathrm{ACN})$ were obtained from VWR International (West Chester, PA). Pepsin and trypsin were obtained from Roche (Indianapolis, IN). The IgG lots were produced and purified by using processes proprietary to Amgen and kept frozen at $-80^{\circ} \mathrm{C}$ until used. Endoprotease LysC was obtained from Roche Diagnostics (Mannheim, Germany).

\section{Sample Pretreatment}

IgG samples were subjected to limited proteolysis and/or reduction to produce the $\operatorname{IgG~Fc}$, IgG $\mathrm{HC}$, and $\operatorname{IgG~Fc} / 2$ fragments. Limited proteolysis was achieved by incubating the IgG samples with endoproteinase Lys-C [12] at a protein/enzyme weight ratio of 400:1 in incubation buffer (0.1M Tris-HCl, $\mathrm{pH} 8.0)$. The incubation was carried out at $37^{\circ} \mathrm{C}$ for $3 \mathrm{~min}$. The reaction was quenched by lowering the $\mathrm{pH}$ to 4.5 with the addition of acetic acid. Reduction was achieved by incubating $0.5 \mathrm{~mL}$ of $\mathrm{IgG}$ or an IgG Fc fragment at a concentration of $2 \mathrm{mg} / \mathrm{mL}$ in denaturing buffer (7.5 M GdnHCl, $120 \mathrm{mM}$ sodium acetate, $\mathrm{pH} 5.0)$ containing $5 \mathrm{mM} \mathrm{TCEP}$, at $37^{\circ} \mathrm{C}$ for $30 \mathrm{~min}$.

\section{Reversed-Phase Chromatography}

Reversed-phase separation of intact IgG and IgG fragments was carried out on an Agilent (Santa Clara, CA) 1100 HPLC system equipped with a Varian diphenyl $2 \times$ $150 \mathrm{~mm}$ column. Typically, $20 \mu \mathrm{g}$ of protein was injected onto the column. The column was held at $95 \%$ Solvent A (0.1\% TFA in water) and 5\% Solvent B (90\% acetonitrile, $10 \%$ water, and $0.1 \%$ TFA in water) for 5 min followed by a 2 min step gradient from $5 \%$ B to $35 \%$ B. Protein elution was achieved with a liner gradient from $35 \%$ B to $46 \%$ B in $40 \mathrm{~min}$. The flow rate and column temperature were maintained at $200 \mu \mathrm{L} / \mathrm{min}$ and $75^{\circ} \mathrm{C}$, respectively, throughout the run.

\section{Mass Spectrometry}

Mass spectrometric analysis was carried out on a Waters (Milford, MA) LCT premier equipped with an ESI source operated in the $\mathrm{W}$ mode. The capillary and cone voltages were set at 2500 and $80 \mathrm{~V}$, respectively. The desolvation gas and source temperatures were set at $350^{\circ} \mathrm{C}$ and $80^{\circ} \mathrm{C}$, respectively. All the other voltages were optimized to provide maximal signal intensity in 
each of the modes. All raw data were processed using Waters Masslynx MaxEnt 1 software to obtain the deconvoluted mass. The instrument was calibrated in the $m / z$ range of 2500 to 4000 using multiply charged ions of a standard antibody with a calculated MW value of $148,251.2 \mathrm{Da}$.

\section{Peptide Mapping}

Reduced and alkylated IgG was buffer exchanged into digestion buffer (1 M Tris, $1 \mathrm{M}$ urea, and $20 \mathrm{mM}$ hydroxylamine at $\mathrm{pH} 7.0$ ) at a protein concentration of $\sim 1 \mathrm{mg} / \mathrm{mL}$ using a NAP-5 column (Amersham Bioscience, Uppsala, Sweden) following the procedure described by the manufacturer. Trypsin digestion was carried out by incubating $1 \mathrm{mg} / \mathrm{mL}$ of sample (in digestion buffer) with $20 \mu \mathrm{g}$ of trypsin at $37^{\circ} \mathrm{C}$ for $4 \mathrm{~h}$, followed by a second addition of $20 \mu \mathrm{g}$ of trypsin. The mixture was allowed to incubate at $37^{\circ} \mathrm{C}$ for 4 additional hours. The resulting tryptic peptides were separated using a Waters Atlantis column, $2.0 \mathrm{~mm} \times 250$ $\mathrm{mm}$. Approximately $20 \mu \mathrm{g}$ of the digested material was injected on the column. Elution was achieved using a linear gradient from $100 \%$ Buffer A (0.1\%FA) to $50 \%$ Buffer A and 50\% Buffer B (90\% acetonitrile 0.085\% FA) in $170 \mathrm{~min}$. The flow rate was maintained at $0.2 \mathrm{~mL} /$ min and the column temperature was held at $50^{\circ} \mathrm{C}$.

\section{N-Glycan Release Assay}

The antibody samples were first diluted to $1 \mathrm{mg} / \mathrm{mL}$ in digestion buffer provided with the Prozyme kit (San Leandro, CA) and deglycosylated by addition of PNGase F (Sigma St Louis, MO) at a weight ratio of 1:100 (PNGase F:antibody) followed by incubation at $37^{\circ} \mathrm{C}$ for $24 \mathrm{~h}$. The cleaved glycoforms were then purified with a Glycoclean $\mathrm{R}$ cartridge from Prozyme (San Leandro, CA) using the procedure described by the manufacturer. The purified glycoforms were then labeled with 2-aminobenzamide following the protocol in the Prozyme labeling kit. Normal phase chromatography was used to separate the labeled carbohydrates. The separation was performed on an Agilent 1100 system equipped with an Amide-80, $4.6 \mathrm{~mm} \times 250 \mathrm{~mm}$, $5 \mathrm{~mm}$ pore size column from Tosoh Biosciences (Grove City, $\mathrm{OH}$ ) and a fluorescence detector with the excitation wavelength set at $330 \mathrm{~nm}$ and the emission wave length set at $420 \mathrm{~nm}$. Buffer A was $50 \mathrm{mM}$ ammonium formate ( $\mathrm{pH} 4.4)$ and Buffer $\mathrm{B}$ was acetonitrile. The gradient employed was $20 \%$ to $53 \%$ Buffer A over 132 min at $0.4 \mathrm{~mL} / \mathrm{min}$, then $53 \%$ to $100 \%$ Buffer A over 5 $\mathrm{min}$ at $0.4 \mathrm{~mL} / \mathrm{min}$ followed by $100 \%$ Buffer A for $5 \mathrm{~min}$ at $1 \mathrm{~mL} / \mathrm{min}$ and re-equilibration in starting conditions for $5 \mathrm{~min}$ at $0.4 \mathrm{~mL} / \mathrm{min}$.

\section{Statistical Analysis}

Results of the LC/MS based assays were compared quantitatively with the standard $N$-glycan release assay using a paired $t$-test, $\alpha=0.05$. The intact $\operatorname{IgG}$ and HC assays were excluded from this comparison because these assays detect paired glycoforms on dimeric proteins, and so cannot be compared quantitatively with the results of the $N$-glycan release assay.

\section{Results}

\section{LC/MS Analysis of Intact IgG Molecules}

Recent advances in rp-LC and ESI-MS have made LC/MS analysis of intact IgGs routine [12, 13]. The diphenyl column used in this study allows IgG separation with acetonitrile and has been shown previously to resolve site-specific modifications in $\operatorname{IgGs}[17,18]$. ESI is the preferred mode of ionization for the analysis of IgG molecules as it produces a multiply charged envelope in the $\mathrm{m} / \mathrm{z}$ range of 2000 to 4000 that can be deconvoluted to obtain the nominal mass. A major constraint in the MS analysis of large proteins is their wide, natural isotopic distribution [13]. Since the full maximum at half width (FMHW) of the isotopic distribution of an IgG molecule is $40 \mathrm{Da}$, small mass changes introduced by modifications such as oxidation $(+16 \mathrm{Da})$ are difficult to resolve for intact IgGs even with high-resolution MS analysis. However, glycosylation variation in IgGs is usually associated with larger mass changes, which can be analyzed by standard time of flight instruments with resolution between 5000 to $15,000 \mathrm{Da}$ [14].

The deconvoluted mass spectra of two different manufacturing lots (Lot a and Lot $b$ ) of a recombinant monoclonal IgG1 analyzed with rp-LC /ESI-TOF are shown in Figure 1. These spectra were obtained by deconvoluting the raw $\mathrm{m} / \mathrm{z}$ spectra (not shown). Both lots of $\operatorname{IgG}$ showed multiple peaks, which can be attributed to the galactose heterogeneity typically found on the $N$-linked glycans present in the conserved region of all $\operatorname{IgG}$ molecules. This typical $N$-glycan profile described in earlier reports [19] is summarized in Table 1 . The $(\mathrm{GOF})_{2}$ peak from Figure 1 contains two biantennary oligosaccharides, one on each heavy chain. The G0F form has three mannose (hexose), four $N$ acetylglucosamine residues, and a fucose residue. This tri-mannosyl core structure (two $\mathrm{N}$-acetylglucosamine residues and the three mannose residues) is typically conserved during the production of $\operatorname{IgG}$ molecules and, hence, is unlikely to be the source of the identified heterogeneity. The terminal galactose residues, however, show significant variability leading to the peaks G0F/G1F, $(\mathrm{G} 1 \mathrm{~F})_{2}$ etc., which are successively $162 \mathrm{Da}$ apart. In addition to these galactose variants, Man5/ Man5 and Man5/G0F structures were also observed. Man5, Man6, Man7, Man8. and Man9 are high mannose carbohydrates; these highly branched precursors of the biantennary carbohydrates contain several branches of mannose residues. The assignment of these peaks was based on their deconvoluted mass. The observed mass for the Man5/Man5 peak agrees well with its calculated mass of 147787 . However, the Man5/G0F peak was 9 


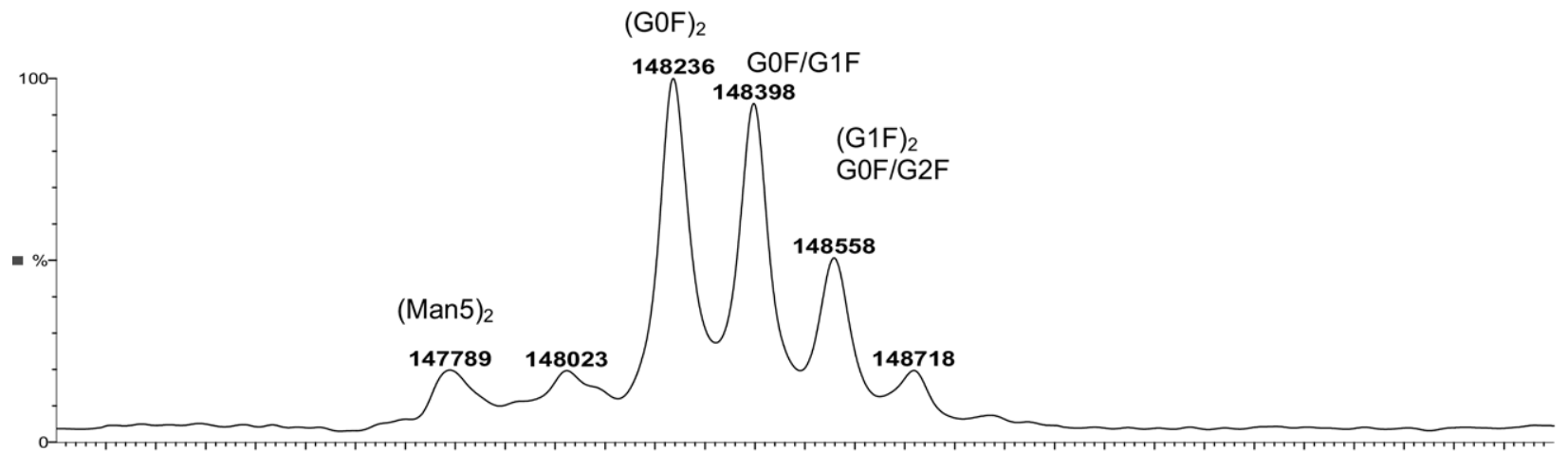

(a)

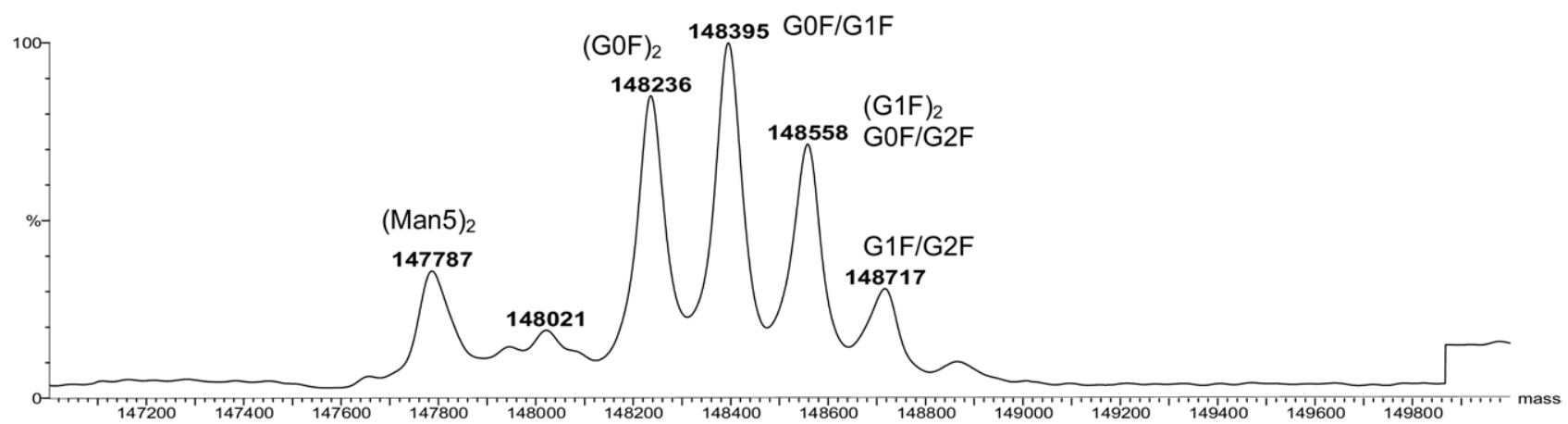

(b)

Figure 1. Deconvoluted spectra of intact IgG. Deconvoluted mass spectra generated from two different lots (a) and (b) of the same recombinant monoclonal antibody. The peak labels refer to the various glycoforms identified based on the deconvoluted mass. For deconvolution, a $\mathrm{m} / \mathrm{z}$ range from 2500 to 3700 was used with the following MaxEnt1 parameters: mass range from 140,000 to 160,000 Da; minimum intensity ratio left and right, $50 \%$; width at half height for uniform Gaussian model, 1.5; number of iterations, 12.

Da less than its calculated mass. The mass for the Man5/G0F peak is within $100 \mathrm{Da}$ of the mass of G0/G0, G0/G0F, and Man5/Man6 glycoforms. As described earlier, the wide isotopic distribution for large proteins makes it difficult to fully resolve these forms. The incomplete resolution of the peaks could result in the larger mass error observed for the Man5/G0F form.

The deconvoluted spectra of the IgG from Lots a and $\mathrm{b}$ show some differences in their glycosylation profiles. The IgG from Lot $b$ had a greater extent of the terminal galactose residues, which was evident from the higher intensities of the G0F/G1F and $(\mathrm{G} 1 \mathrm{~F})_{2}$ peaks. We have shown previously that the intensities of the peaks from the deconvoluted spectra can be accurately used for quantitation of the hexose index $\left(\mathrm{Hex}_{\mathrm{I}}\right)$, which is the molar ratio of galactose residues per molecule of $\operatorname{IgG}$ [14]. Additionally, the IgG from Lot b also showed greater amounts of the high mannose containing peaks than the IgG from Lot a.

These data indicate that LC/MS analysis of intact IgG can be an adequate method for the high level analysis of glycoforms on IgG molecules. Due to minimal sample preparation involved, this method is adaptable to high throughput analysis. A critical limitation that becomes apparent in comparison with the other methods is that low abundance glycoforms are not detected, particularly many of the high mannose containing glycoforms (see e.g., Figure 2). In addition, individual glycoforms cannot be quantified, since the method only provides the total masses of paired glycoforms. Because of these limitations, the results of the intact IgG assay were excluded from further quantitative comparisons (see Table 2). Analysis of intact IgG could find application as a rapid screening method during cell culture development.

\section{LC/MS Analysis of IgG-Fc}

The hinge region of an IgG is highly solvent exposed and susceptible to proteolytic cleavage. Limited proteolysis of IgG molecules has been widely used to generate IgG subunits, which are generally more amenable to LC/MS analysis than the intact molecule [20] [21]. Pepsin and papain have been classically used to clip below and above the hinge region to generate $\mathrm{F}(\mathrm{ab})^{\prime}{ }_{2 \text {, }}$ $\mathrm{Fab}$, and Fc fragments. We have recently developed a method for the limited proteolysis of human IgG1 $\mathrm{mAbs}$ using endoproteinase Lys-C [12]. Limited proteolysis with Lys-C causes a single cleavage at the Cterminus of a lysine residue located in the hinge region 
Table 1. Structure, nomenclature and molecular weight of the carbohydrate moieties typically observed in recombinant monoclonal IgG molecules

\begin{tabular}{|c|c|c|}
\hline Oligosaccharide structure & Code & $\begin{array}{c}\text { Mass } \\
(\mathrm{Da})\end{array}$ \\
\hline $\begin{array}{l}G-G N-M \\
G-G N-M\end{array}$ & $\mathrm{G} 2 \mathrm{~F}$ & 1769.6 \\
\hline $\begin{array}{r}G-G N-M>M-G N-G^{F}- \\
G N-M\end{array}$ & $\mathrm{G} 1 \mathrm{~F}$ & 1607.5 \\
\hline $\begin{array}{l}G N-M>M-G N-G^{F}- \\
G N-M\end{array}$ & GoF & 1445.4 \\
\hline $\begin{array}{l}M \\
M\end{array}-M \geq M-G N-G N-$ & Man5 & 1217.2 \\
\hline $\begin{array}{l}M>M \\
M \\
M\end{array}-M=M-G N-G N-$ & Man6 & 1379.3 \\
\hline $\begin{array}{l}M \\
M-M \\
M-M\end{array}-M-G N-G N-$ & Man7 & 1541.4 \\
\hline $\begin{array}{l}M-M>M \\
M-M-M \\
M-M-G N-G N-\end{array}$ & Man8 & 1703.5 \\
\hline$G N-\frac{M}{M} \geq M-G N-G_{N}^{F}-$ & GOF-GIcNac & 1242.2 \\
\hline$G-G N-\frac{M}{M}>M-G N-G N$ & G1F-GIcNac & 1404.3 \\
\hline 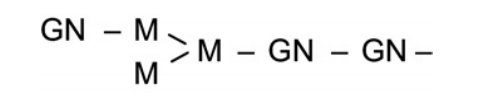 & G0-GlcNac & 1096.1 \\
\hline $\begin{array}{l}G-G N-M \backslash M-G N-G N- \\
G-G N-M^{\prime}=M-\end{array}$ & G2 & 1623.5 \\
\hline $\begin{aligned} G-G N-M & -M-G N-G N- \\
G N-M & \end{aligned}$ & $\mathrm{G} 1$ & 1461.4 \\
\hline $\begin{array}{l}G N-M>M-G N-G N- \\
G N-M\end{array}$ & G0 & 1299.3 \\
\hline
\end{tabular}

to generate an Fc and two Fab fragments. Limited proteolysis with Lys-C maintains the disulfide structure of the Fc and Fab domains and, hence, allows the characterization of modifications in the disulfide architecture. In addition, limited proteolysis also conserves the oligosaccharide pairing in the $\mathrm{CH} 2$ domain.

The deconvoluted spectra of the IgG-Fcs from the two lots generated after limited proteolysis with Lys-C are shown in Figure 2. IgG-Fc, with a mass of $\sim 50 \mathrm{kDa}$, is roughly one-third the molecular weight of the intact IgG molecule. Hence, IgG-Fc has a much smaller normal isotopic distribution with a FMHW of $\sim 15 \mathrm{Da}$, which allows for improved isoform resolution. This is evident from the spectra in Figure 2, which shows the resolution of several additional peaks such as Man5/ Man6, Man5/Man7, G0/G0F, etc. The pairing of different high mannose structures can lead to several isobaric peaks. For example, Man6/Man6 and Man5/Man7 both have the same mass, but for simplicity only one form (the most predominant) was used for labeling. Overall, this method of glycoform analysis of IgG-Fc yields at least 10 additional peaks compared with the analysis of intact IgG. However, some forms of the carbohydrate could not be fully resolved in these analyses. The forms Man5/G0F and G-GlcNAc/G0F vary in mass by only $25 \mathrm{Da}$ and were not fully resolved. A partial resolution of these forms was obtained in the deconvoluted spectrum of Lot B from Figure 2.

Analysis of intact IgG and IgG-Fc allows the determination of oligosaccharide pairing, an effect described previously by Masuda et al. [19]. Oligosaccharide pairing can lead to a symmetric or asymmetric Fc portion. Symmetric molecules have identical carbohydrates on each chain while asymmetric molecules have different carbohydrates on the two HCs. The study of pairing is important as each of the carbohydrates on the HC can have a cooperative and an additive effect on Fc function [19]. In both lots, the symmetric Man5/Man5 form was more abundant than the asymmetric Man5/G0F form. Since the GOF form was significantly greater than the Man5, a binomial distribution would lead to a greater amount of the asymmetric Man5/G0F form than the Man5/Man5 form. However, in both lots, the Man5/ Man5 form was greater in abundance than the Man5/ G0F, indicating a preferential pairing of the Man/ 5Man5 form. This preferential pairing could be the result of structural limitations imposed on the asymmetric Man5/G0F form or could be caused by cell culture parameters such as antibody titer, production time, or other factors inherent to the cell line itself. LC/MS analysis of the intact $\operatorname{IgG}$ and $\mathrm{IgG}-\mathrm{F}_{\mathrm{C}}$ is the only method that allows detection of oligosaccharide pairing in the IgG molecule.

While the detection of low abundance glycoforms is improved by the analysis of IgG-Fc rather than intact IgG, the method does not provide for the quantitation of individual glycoforms but only glycoform pairs (see below). The results of LC/MS analysis of IgG-Fc have thus been excluded from the quantitative comparison (see Table 2). 


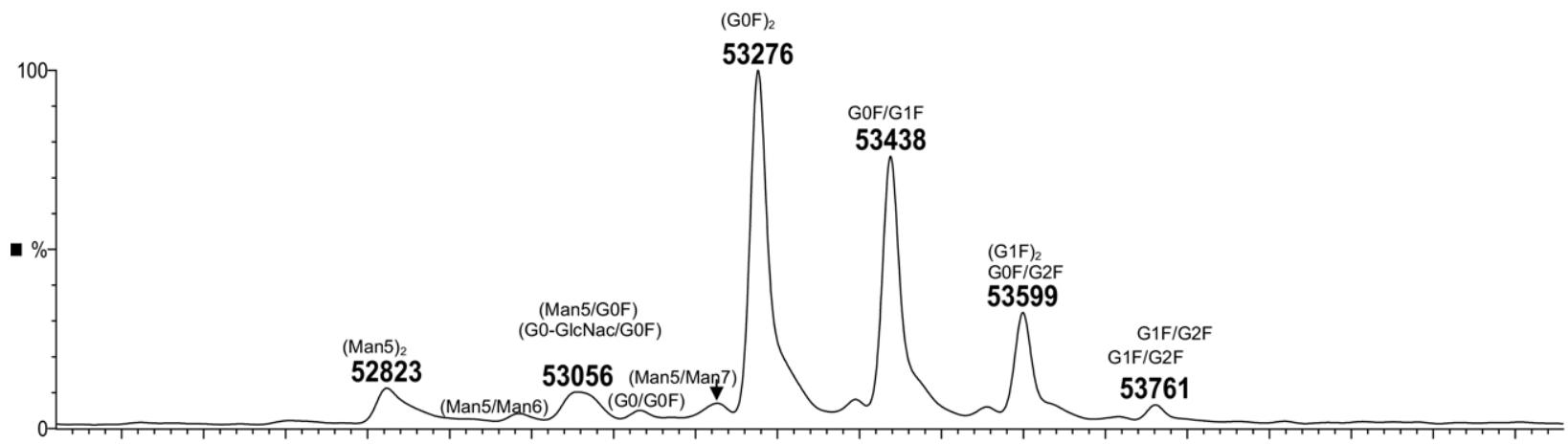

(a)

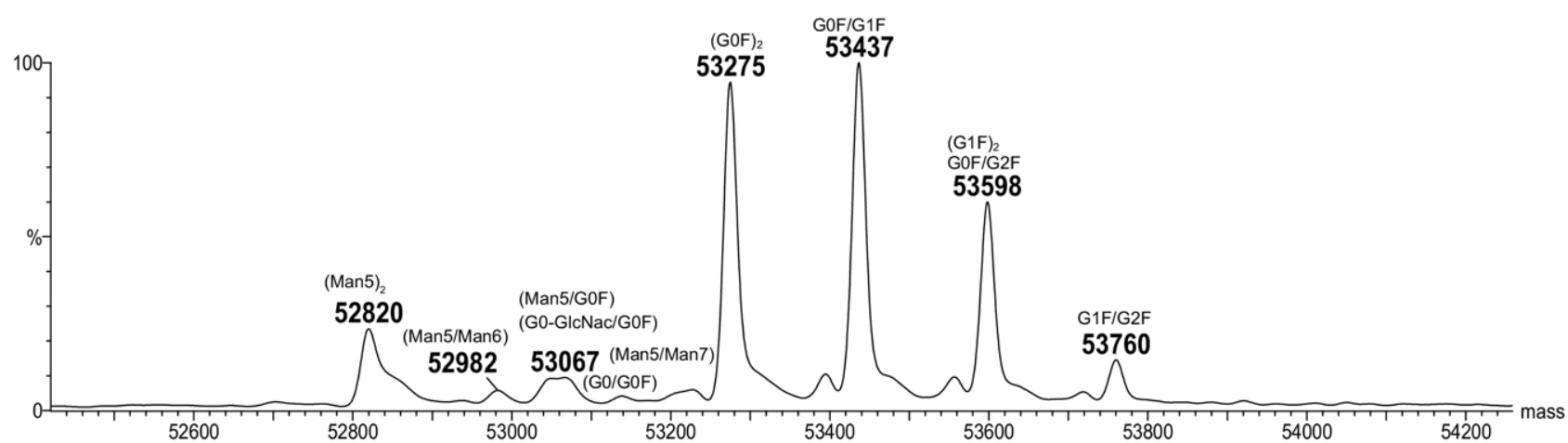

(b)

Figure 2. Deconvoluted spectra of intact IgG Fc. Deconvoluted mass spectra of IgG-Fc generated from two different lots (a) and (b) of the same recombinant monoclonal antibody. The peak labels refer to the various glycoforms identified based on the deconvoluted mass. For deconvolution, a $\mathrm{m} / \mathrm{z}$ range from 1500 to 3000 was used with the following MaxEnt1 parameters: mass range from 40,000 to 60,000 $\mathrm{Da}$; minimum intensity ratio left and right, $50 \%$; width at half height for uniform Gaussian model, 0.8 ; number of iterations, 12.

\section{LC/MS Analysis of IgG-HC}

Reduction of an IgG into individual heavy chains (HCs) and light chains is another way to create IgG subunits and is often performed before analysis. The IgG HC, which contains the carbohydrate is around $50 \mathrm{kDa}$, similar in size to the IgG-Fc. Analysis of the HC is more straightforward since reduction removes the complexity caused by the pairing of oligosaccharides when the

Table 2. Quantitation of the IgG glycoforms with various analytical methods: reduced (HC), limited and reduced (Fc/2), extracted ion (XIC), and N-glycan release assay

\begin{tabular}{|c|c|c|c|c|c|c|c|c|}
\hline \multirow[b]{2}{*}{ Sugars } & \multicolumn{2}{|c|}{ Reduced (HC) } & \multicolumn{2}{|c|}{ Limited and reduced $(\mathrm{Fc} / 2)$} & \multicolumn{2}{|c|}{ Extracted ion $(\mathrm{XIC})$} & \multicolumn{2}{|c|}{$\mathrm{N}$-glycan release } \\
\hline & $\lg \mathrm{A}(\%)$ & $\operatorname{lgG} B(\%)$ & $\lg \mathrm{A}(\%)$ & $\lg \mathrm{B}(\%)$ & $\lg \mathrm{A}(\%)$ & $\lg \mathrm{B}(\%)$ & $\lg \mathrm{A}(\%)$ & $\lg G \mathrm{~B}(\%)$ \\
\hline Man5 & $9.6 \pm 0.5$ & $10.8 \pm 0.5$ & $9.0 \pm 0.3$ & $11.2 \pm 0.05$ & $17.2 \pm 0.6$ & $18.1 \pm 1.4$ & $11.0 \pm 0.5$ & $12.9 \pm 0.5$ \\
\hline GOF - GN & ND & ND & $5.0 \pm 0.8$ & $5.4 \pm 0.07$ & $4.0 \pm 0.2$ & $6.2 \pm 0.4$ & $6.4 \pm 0.2$ & $6.0 \pm 0.2$ \\
\hline G1F - GN & ND & ND & ND & ND & ND & ND & $1.8 \pm 0.07$ & $1.3 \pm 0.2$ \\
\hline G0 & ND & ND & $2.0 \pm 0.02$ & ND & $0.8 \pm 0.1$ & ND & ND & ND \\
\hline Man6 & ND & ND & $2.7 \pm 0.2$ & $2.6 \pm 0.2$ & $1.0 \pm 0.2$ & $1.3 \pm 0.2$ & $2.7 \pm 0.2$ & $3.0 \pm 0.09$ \\
\hline Man6* & ND & ND & ND & ND & ND & ND & $0.6 \pm 0.05$ & $1.0 \pm 0.04$ \\
\hline GOF & $55.8 \pm 1.0$ & $44.1 \pm 0.3$ & $39.7 \pm 0.6$ & $36.0 \pm 0.3$ & $68.3 \pm 1.5$ & $60.7 \pm 1.2$ & $46.9 \pm 1.3$ & $40.3 \pm 0.7$ \\
\hline $\mathrm{G} 1$ & ND & ND & $9.7 \pm 0.3$ & $6.67 \pm 0.06$ & ND & ND & ND & ND \\
\hline Man7 & ND & ND & $2.9 \pm 0.09$ & $1.86 \pm 0.07$ & ND & ND & $2.1 \pm 0.3$ & $2.8 \pm 0.2$ \\
\hline $\mathrm{G} 1 \mathrm{~F}$ & $31.0 \pm 1.4$ & $38.0 \pm 0.4$ & $22.6 \pm 0.1$ & $26.4 \pm 0.1$ & $8.3 \pm 0.6$ & $12.9 \pm 0.5$ & $16.8 \pm 0.3$ & $19.3 \pm 0.4$ \\
\hline $\mathrm{G} 1 \mathrm{~F}^{*}$ & ND & ND & ND & ND & ND & ND & $6.4 \pm 0.2$ & $7.4 \pm 0.4$ \\
\hline $\mathrm{G} 2$ & ND & ND & $6.1 \pm 0.3$ & $4.9 \pm 0.1$ & ND & ND & ND & ND \\
\hline Man8 & ND & ND & $1.7 \pm 0.05$ & $0.73 \pm 0.03$ & ND & ND & ND & ND \\
\hline $\mathrm{G} 2 \mathrm{~F}$ & $3.6 \pm 0.5$ & $7.0 \pm 0.4$ & $3.4 \pm 0.1$ & $4.21 \pm 0.02$ & $0.3 \pm 0.06$ & $0.7 \pm 0.05$ & $3.5 \pm 0.2$ & $4.7 \pm 0.5$ \\
\hline
\end{tabular}

$\mathrm{ND}=$ not detected, ${ }^{*}=$ Isobaric form of that listed in the preceding row. $\mathrm{N}=6+/$ - standard deviation. 
two IgG HCs are linked, reducing the number of different analytes possible. For example, if five different glycoforms may be covalently attached to the heavy chains, the number of different masses expected for the $\mathrm{HC}$ fragment is five. In samples containing the dimeric heavy chain (i.e., IgG, IgG Fc), however, the number of possible masses is $2^{5}=32$, a consequence of the fact that different glycoforms may be linked to each of the heavy chains. Reduction of the IgG into monomeric HC fragments does result in fewer peaks, as shown in the deconvoluted spectra in Figure 3. The spectra of the HC show the biantennary oligosaccharides G0F, G1F, and G2F, along with smaller amounts of the high mannose forms. The paired glycoforms detected in intact IgG and IgG-Fc samples (e.g., Man5/Man5, G0F/G1F, Figures 1, 2) are absent, however, as expected. Since in the analysis of IgG-HC the pairing effect is removed, the intensity of peaks for the various carbohydrate structures can be used to quantify the various glycoforms. The MaxEnt algorithm used for generating the deconvoluted spectra preserves the intensity information from the raw spectra, allowing accurate quantitation.

\section{LC/MS Analysis of IgG-Fc/2}

$\mathrm{Fc} / 2$ refers to the constant region of the single $\mathrm{HC}$ and is produced after reduction of the Fc. Fc/2 is $\sim 25 \mathrm{kDa}$, is half the size of the $\mathrm{HC}$, and has a smaller normal isotopic distribution that allows for greater resolution of modifications. The deconvoluted spectra of $\mathrm{Fc} / 2$ from the two different lots are shown in Figure 4. Compared with the deconvoluted spectra of HC (Figure 3), the $\mathrm{Fc} / 2$ spectra showed improved resolution for the various glycoforms, which was clearly observed in peaks such as Man5 and G0F-GlcNAc. Additional low intensity peaks such as G0 were more clearly visible in the spectra for $\mathrm{Fc} / 2$. The improved detection of low intensity peaks could be the result of improved signal to noise of the more compact peaks in $\mathrm{Fc} / 2$. The higher sensitivity led to the identification of a greater number

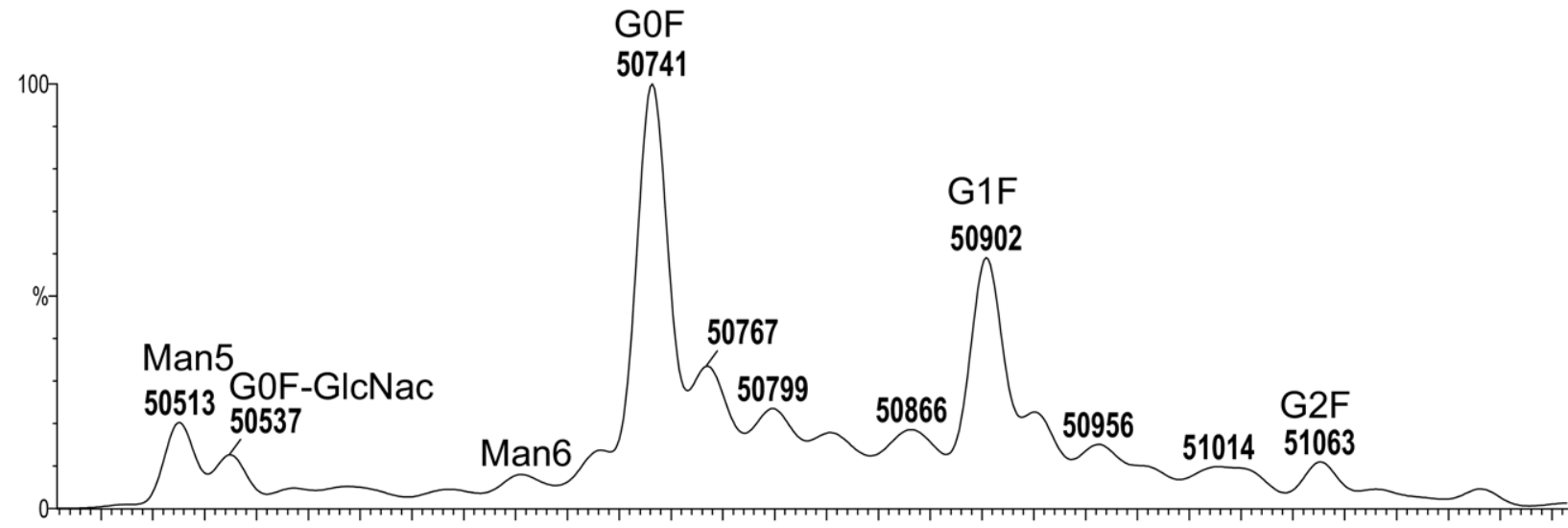

(a)

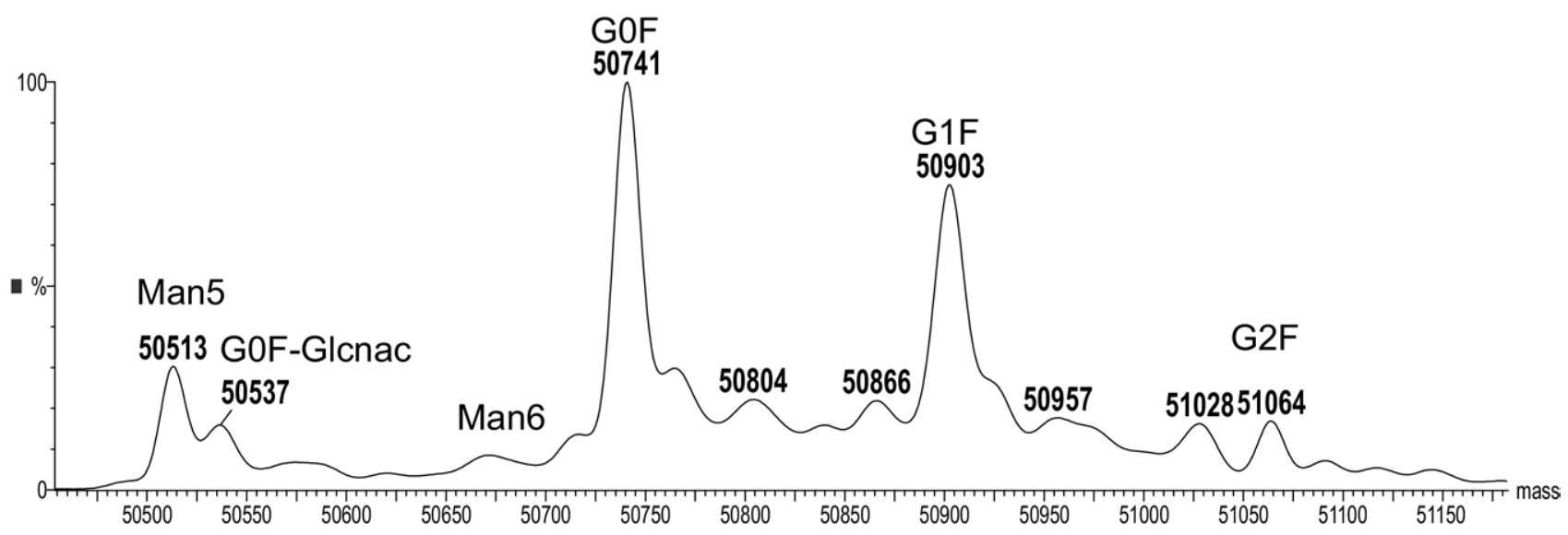

(b)

Figure 3. Deconvoluted spectra of intact IgG HC. Deconvoluted mass spectra of heavy chains (IgG-HC) generated from two different lots (a) and (b) of the same recombinant monoclonal antibody. The peak labels refer to the various glycoforms identified based on the deconvoluted mass. For deconvolution, a $\mathrm{m} / \mathrm{z}$ range from 1500 to 3000 was used with the following MaxEnt 1 parameters: mass range from 40,000 to $60,000 \mathrm{Da}$; minimum intensity ratio left and right, $50 \%$; width at half height for uniform Gaussian model, 0.8; number of iterations, 12. 


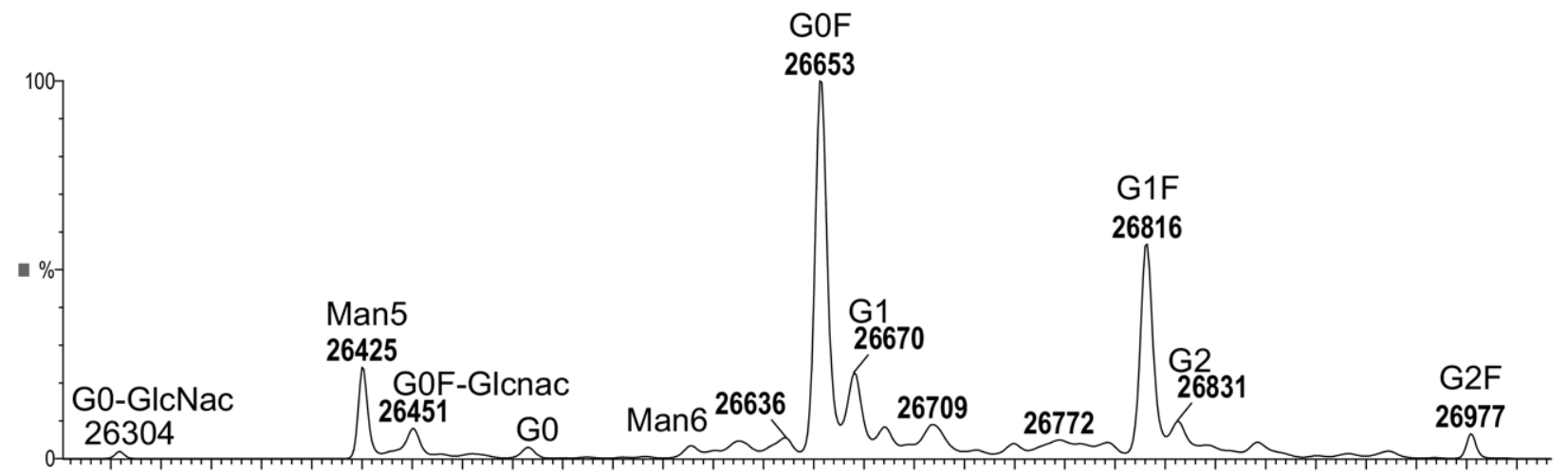

(a)

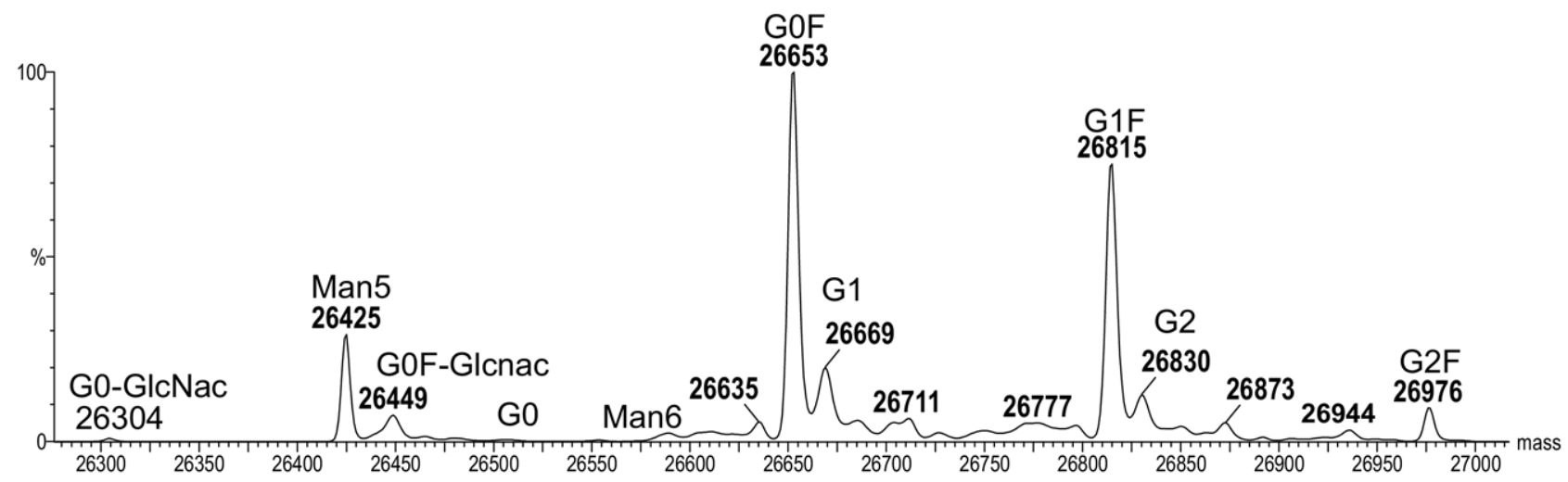

(b)

Figure 4. Deconvoluted spectra of intact $\operatorname{IgG} \mathrm{Fc}_{\mathrm{C}} / 2$. Deconvoluted mass spectra of $\mathrm{IgG}-\mathrm{Fc} / 2$ generated from two different lots (a) and (b) of the same recombinant monoclonal antibody. The peak labels refer to the various glycoforms identified based on the deconvoluted mass. For deconvolution, a $\mathrm{m} / \mathrm{z}$ range from 1500 to 3000 was used with the following MaxEnt1 parameters: mass range from 20,000 to $40,000 \mathrm{Da}$; minimum intensity ratio left and right, $50 \%$; width at half height for uniform Gaussian model, 0.5 ; number of iterations, 12.

of glycoforms in the Fc/2 spectra. For example, while G0, G1, and G2 carbohydrates were not observed in the intact IgG, IgG-Fc, or HC spectra, they were detected in the $\mathrm{Fc} / 2$ spectra. Similar to the previous analyses, the amount of the high mannose forms was higher in Lot $b$. Glycoforms with a mass difference as low as 25 Da were baseline-resolved, which subsequently allowed improved quantitation of these forms. All the peak assignments in the deconvoluted spectra were based on the calculated mass with errors less than 200 parts per million (ppm).

\section{LC/MS Analysis After Trypsin Digestion (XIC Method)}

Tryptic peptide mapping is commonly used to determine chemical modifications and sequence variants in proteins [22]. Peptide mapping relies on specific cleavage of the protein sequence with a proteolytic enzyme such as trypsin, giving rise to a known set of peptides. The subsequent LC/MS allows determination of site specific modifications in proteins. Peptide mapping has been widely used for the characterization of IgG mole- cules. Complete trypsin cleavage of IgG1 molecules generates the peptide 293EEQYNSTYR301, which contains the N-linked carbohydrate moiety on N297. Standard reversed-phase separation methods may not resolve the various glycoforms on the peptide. However, each glycoform (apart from isobaric structures) can be distinguished by its specific mass. The intensities specific to the glycoforms can be obtained from the total ion chromatogram (TIC) by generating extracted ion chromatograms (XIC). XICs are generated by extracting the ion signal for the mass of a particular peptide from the total ion chromatogram acquired on the mass spectrometer. This method allows the analysis of a specific compound in a mixture of analytes. Figure 5 shows the peptide maps (inlays) and XICs for the various glycoforms in the two lots. This method had a low sensitivity, and only five glycoforms (Man5, Man6, G1F, G0F, and GOF-GlcNAc) could be detected. XICs of other glycoforms, which were detected in the previous analyses, did not show measurable peaks (not shown). A difference in retention of the glycoforms was observed, and highly branched structures (high mannose) had a shorter retention time than the biantennary structures. 


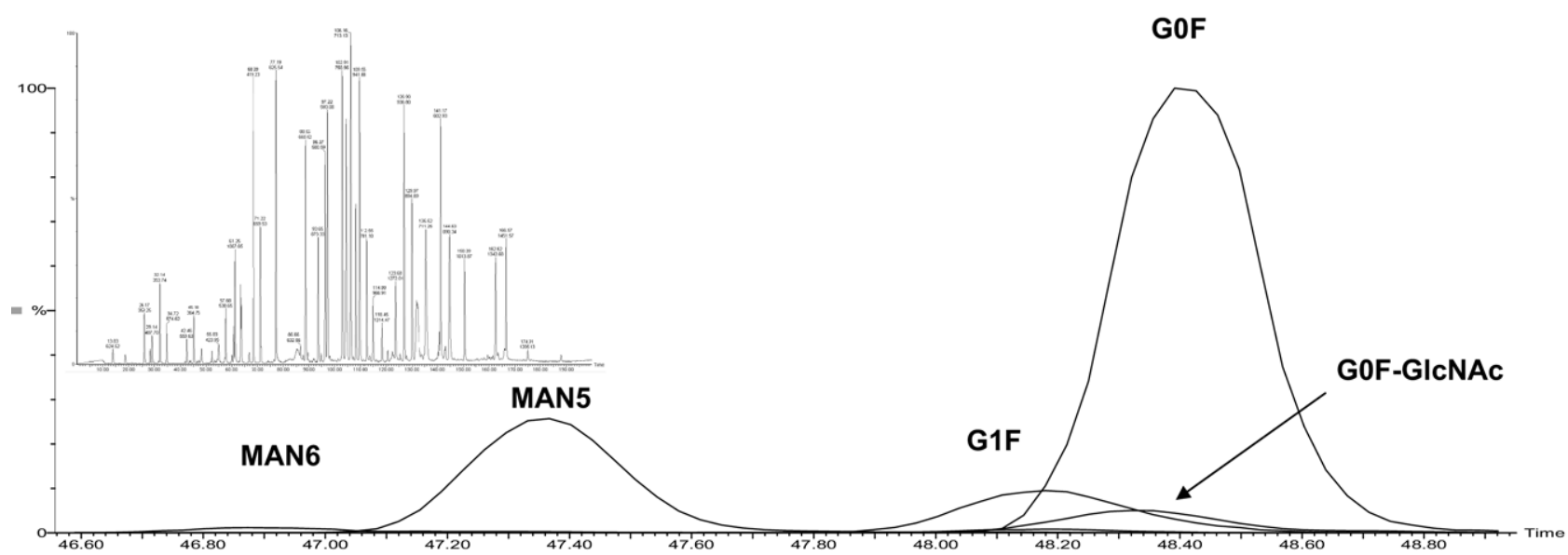

(a)

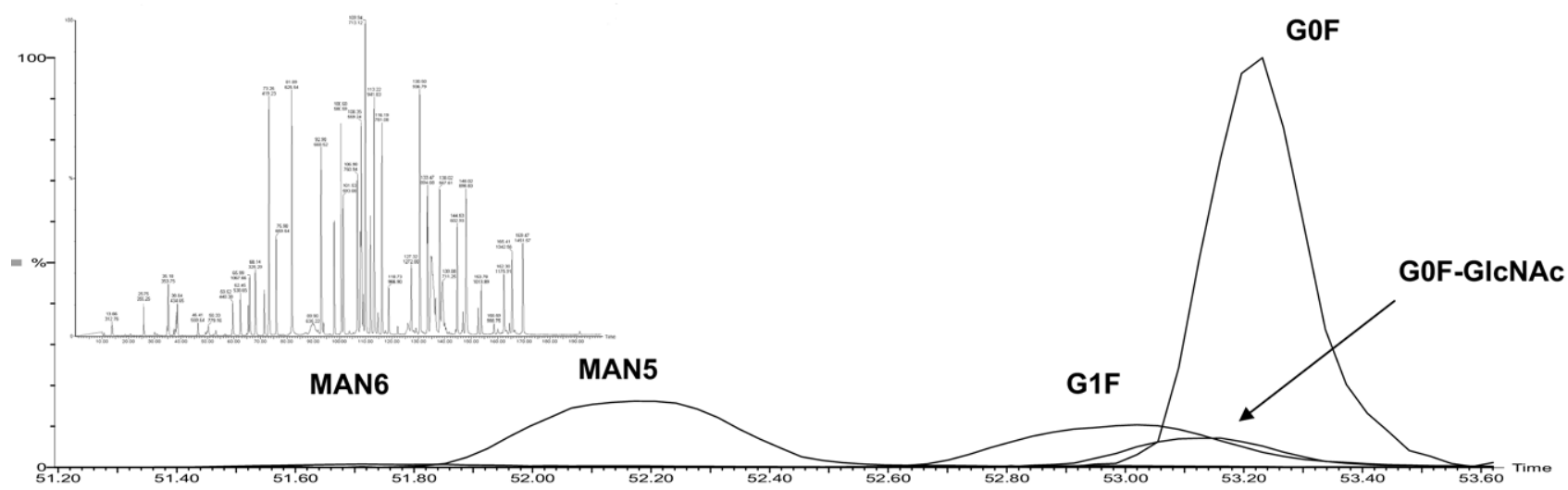

(b)

Figure 5. Extracted ion chromatograms (XIC) for the various glycoforms. Peptide maps of IgGs from two different lots (a) and (b) of the same recombinant monoclonal antibody are shown in the inlays. The extracted ion chromatograms (XICs) from the peptide maps of the two lots are shown. The peak labels refer to XICs of the doubly charged ion for the various glycoforms. The following masses were used to generate the XICs: G0F; 1318.3, G1F; 1399.4, G2F; 1480.5, G0F-GlcNAc; 1217.2, Man5; 1204.7 and Man6; 1285.7.

Similarly, the size of the carbohydrate moiety also affected their retention.

\section{N-Glycan Release Assay}

An $\mathrm{N}$-glycan release assay is the most commonly used method for the quantitation of glycoforms in IgG molecules and other glycoproteins. For this assay, the $\mathrm{N}$-linked carbohydrate is released from the protein with PNGase F or other glycanases specific for $\mathrm{N}$-linked glycans. The released $\mathrm{N}$-glycans are purified from the protein and analyzed with normal-phase chromatography [23], MALDI, or other techniques [24, 25]. In most cases, the released oligosaccharides are derivatized through their reactive reducing end before analysis. Derivatization is used to introduce fluorescent tags, which improve the normal-phase separation as well as the sensitivity of detection [16]. The chromatograms of PNGase F released oligosaccharides from the two lots, derivatized with 2-aminobenzamide and separated with normal-phase chromatography, are shown in Fig- ure 6a. The glycoform profile shown in Figure 6a agrees very well with that published by Hill et al. [16]. Additional online MS analysis was carried out to identify the peaks separated by normal-phase chromatography (Figure 6b). For simplicity, only the mass spectra for G0F-GlcNAc, Man5, and G0F peaks are shown in Figure $6 \mathrm{~b}$. Similar mass spectra were obtained for other peaks as well. In a previous study by Hill et al. [16], retention of a standard dextran ladder and glucose unit values for each oligosaccharide were used for assignment of peaks from the normal-phase chromatogram. According to that assignment, Man5 was reported to elute just before the G0F peak, while the peak eluting after G0F was assigned as Man6. However, our LC/MS data clearly shows Man5 to elute after the G0F peak, while the peak eluting before G0F was assigned as a mixture of G0F-GlcNAc and G0 (Figure 6b). The MS analysis allowed a more accurate identification leading to reassignment of the high mannose peaks. The highly branched nature of the high mannose oligosaccharides probably leads to a stronger interaction with the normal- 
phase column causing these forms to be retained more than the corresponding biantennary structures with higher glucose unit values. LC/MS analysis also al- lowed the identification of several new peaks such as G0-GlcNAc and G0 which were detected but not assigned in the previous study by [16] (Figure 6a). In

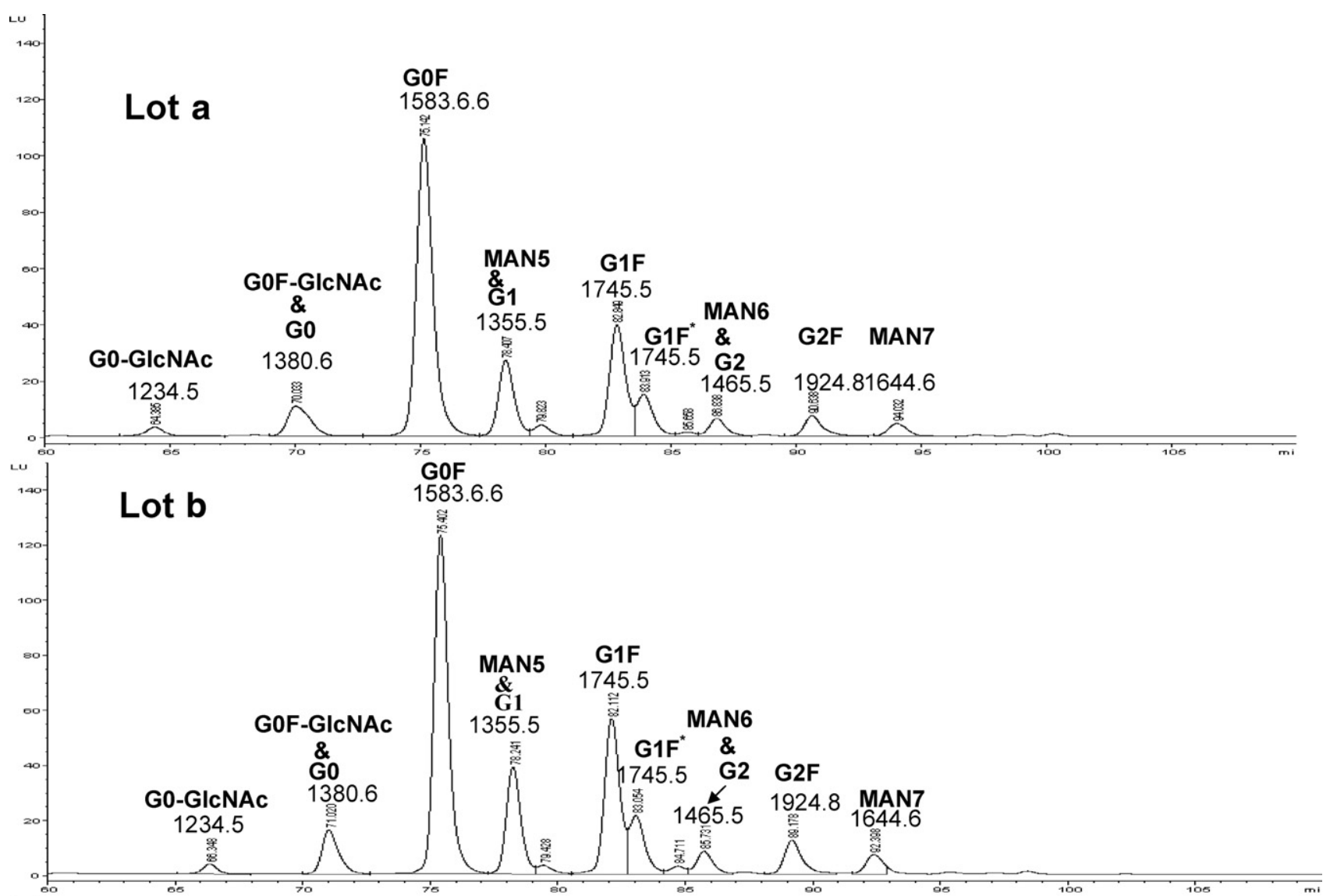

(a)
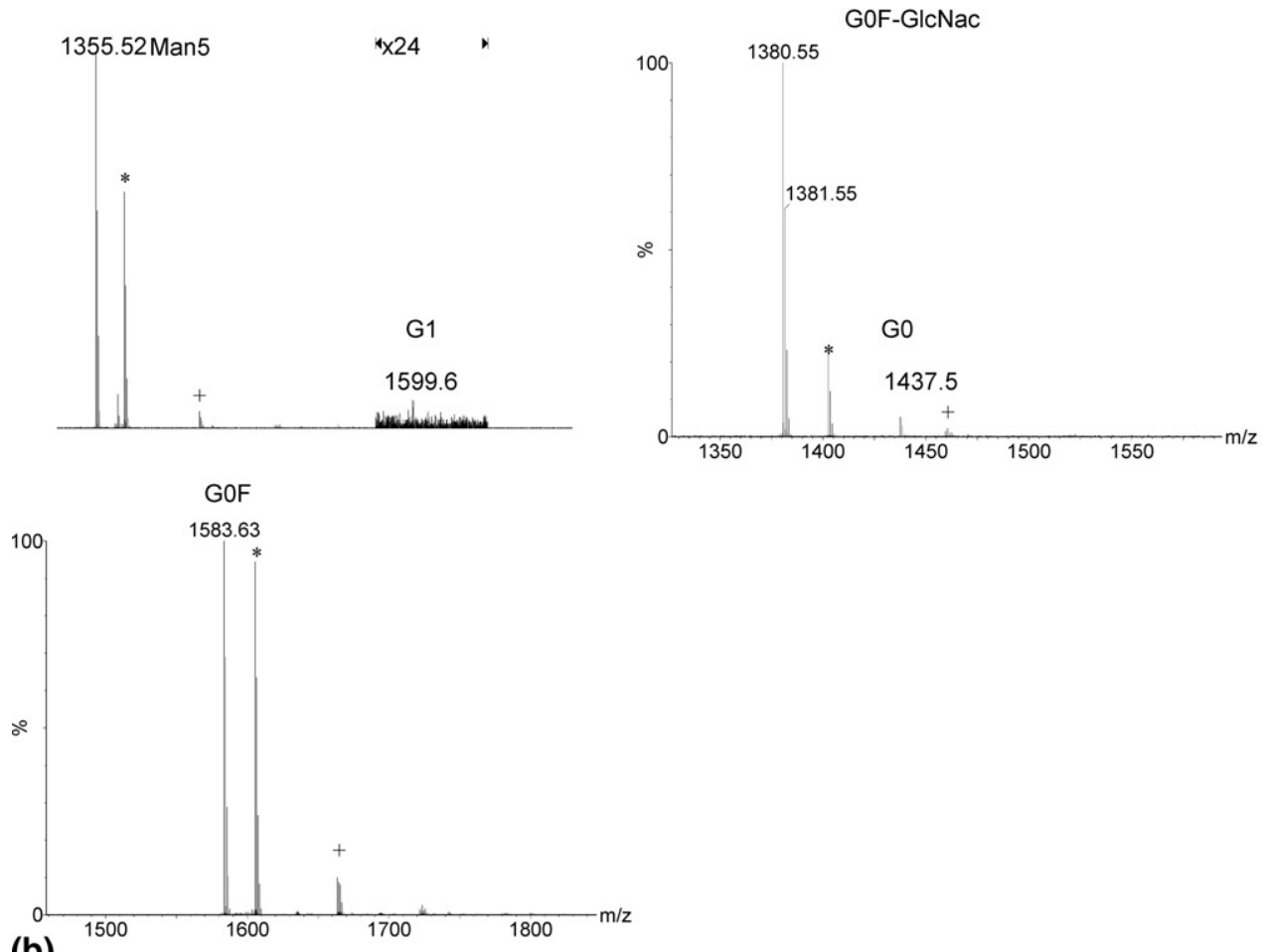

(b) 
addition, the MS analysis showed that the normalphase method could not fully resolve all the glycoforms. G0F-GlcNAc and G0, as well as Man5 and G1 were found to coelute. The low MS signal for G1 (Figure 6b) may be due to ion suppression of the branched Man5 carbohydrate. Since elution in normal-phase chromatography is generally influenced by the amount of carbohydrate, the G2 form would be expected to coelute with the Man6 form. However, the spectra for the Man6 form did not show the presence of the G2 form (data not shown). The coelution of these carbohydrate structures is a major limitation in quantitation using the $N$-glycan release assay.

\section{Quantitative Comparison of Assay Results}

The quantitation of glycoforms by four different methods is summarized in Table 2. As noted in sections above, LC/MS analysis of intact IgG and of IgG-Fc are not included in the quantitative comparison because these methods do not detect individual glycoforms but only glycoform pairs. Table 2 summarizes the quantitative analysis of glycosylation by the four methods that detect monomeric (i.e., unpaired) glycoforms. The methods differ in both the number of glycoforms detected and in the quantitative distribution of the glycoforms. Note that in Table 2 the total percentages of all glycoforms sum to $100 \%$ for each of the methods. This introduces bias in quantitative comparison of methods that detect different numbers of glycoforms. To allow for more accurate comparison, percentages were rescaled to include only the four glycoforms detected by all four methods (i.e., Man5, G0F, G1F, G2F). In addition, isobaric forms that were resolved by the $N$-glycan release assay (i.e., Man6 and Man6*, G1F and G1F*) were pooled for this comparison.

The number of glycoforms detected by the reduced (HC) and extracted ion (XIC) methods are less than by the other two methods (Table 2). Low abundance glycoforms, accounting for less than $\sim 5 \%$ of the total, are infrequently detected by the HC and XIC methods. For example, with the exception of G2F, the HC method does not detect any of the glycoforms that are at less than $5 \%$ abundance by the $N$-glycan release assay. While the XIC method detects some of these low abundance glycoforms (e.g., Man6, G0), low abundance forms with higher mass (e.g., G2) are not detected. In contrast, the limited and reduced $\left(\mathrm{Fc}_{\mathrm{C}} / 2\right)$ assay detects
11 glycoforms for Lot A and 10 glycoforms for Lot B, comparable with the 10 glycoforms detected for each antibody by the $N$-glycan release assay (Table 2 ).

It can also be seen from Table 2 that for Man5, G1F, and G2F, values obtained by the HC and XIC methods differ significantly from those obtained by the $N$-glycan release assay. The XIC results also differ significantly from the $N$-glycan release assay for the most abundant glycoform, G0F. In contrast, the results of the $\mathrm{Fc} / 2$ method are not significantly different from those of the $\mathrm{N}$-glycan release assay for any of the four major glycoforms. Thus, the Fc/2 assay provides results that are comparable to the $N$-glycan release assay in both the number of glycoforms detected and the quantitative values.

Several reasons can be proposed for the quantitative and qualitative differences among the four methods. The poor ability of the HC method to detect glycoforms and to provide quantitative agreement with the standard $N$-glycan release assay may reflect poor ionization of the relatively large $(\sim 50 \mathrm{kD})$ glycosylated $\mathrm{HC}$ molecule. The XIC method may be susceptible to suppression of the glycopeptide signal due to the attached carbohydrate for the relatively small peptide fragments produced by digestion. The good agreement between the $\mathrm{Fc} / 2$ assay and the standard $N$-glycan release assay may be due in part to the improved ionization of this glycosylated protein, intermediate in size $(\sim 26 \mathrm{kD})$ between the HC and XIC fragments.

While the $N$-glycan release assay is regarded as a standard in monitoring IgG glycosylation, it is not without limitations. Of the methods studied here, only the $N$-glycan release assay could detect and resolve isobaric glycoforms (i.e., Man6 and Man6*, G1F and $\mathrm{G}^{*} \mathrm{~F}^{*}$, Table 2). The $N$-glycan release assay also showed high precision as reflected by the low standard deviation. However, online mass spectrometric analysis showed coelution of some of the carbohydrate structures during the $N$-glycan release assay, which greatly restricts its ability to quantitate these glycoforms. In particular, values for the Man5 and G0-GlcNAc reported for the $\mathrm{N}$-glycan release assay in Table 2 are not accurate because these carbohydrate structures coelute with the G0 and G1 forms, respectively, making their quantitation suspect.

Overall, the quantitation obtained with the $\mathrm{Fc} / 2$ assay was comparable to that of the $N$-glycan release assay and the small differences observed can be attrib-

Figure 6. N-glycan release assay of the two IgG lots. (a) Normal-phase chromatograms of aminobenzamide labeled carbohydrates from two different lots (a) and (b) of the same recombinant monoclonal antibody. The peak labels refer to various glycoforms identified based on the mass; (b) $\mathrm{m} / \mathrm{z}$ spectra of peaks from Figure 6(a). The identification was based on the accurate mass of the aminobenzamide labeled carbohydrates. Peaks labeled with an asterisk and a plus symbol represent sodium and sulfate adducts. The theoretical mass $(\mathrm{M}+\mathrm{H})$ of the amino benzoic acid forms of the carbohydrate structures are as follows: G0F; 1583.53, G0; 1437.4; G0F-GlcNAc; 1380.3 Man5; 1355.3 and G1; 1599.5. The trace for the G1 peak was magnified $24 \times$ to enable display in the presence of a strong signal of the Man5 peak. 
uted to coelution of certain forms during the $\mathrm{N}$-glycan release assay. A limitation of the $\mathrm{Fc} / 2$ assay, and of any $\mathrm{rpLC} / \mathrm{MS}$ approach, is that isobaric structures (i.e., Man6 and Man6*, G1F and G1F*) cannot be resolved with this method. The $\mathrm{Fc} / 2$ and $\mathrm{N}$-glycan release assays thus are highly complementary and, when used together, are expected to provide complete characterization of carbohydrates in therapeutic recombinant monoclonal IgG molecules.

\section{Conclusions}

The studies reported here highlight strengths and limitations of LC/ESI-TOF MS assays for the identification and quantitation of glycoforms in IgGs. ESI-TOF analysis of the intact IgG was able to adequately measure the galactose variance in the biantennary $\mathrm{N}$-glycan structure, but could not resolve the heterogeneity caused by high-mannose carbohydrates. ESI-TOF analysis of the IgG-Fc fragment generated after limited proteolysis enabled detection of both biantennary and high-mannose carbohydrates, and was effective in characterizing oligosaccharide pairing caused by the combination of glycans on the two IgG-Fc heavy chains. Neither the intact IgG nor the IgG Fc analysis was found to provide sufficient resolution for quantitation, however. ESI-TOF analysis of the IgG-Fc/2 fragment showed accurate quantitation of various biantennary and high-mannose oligosaccharides, and was the most effective of the MS based methods evaluated at identification and quantitation. Peptide mapping followed by ESI-TOF MS analysis was not effective for absolute quantitation, as the ionization of glycopeptides was influenced by the size of the carbohydrate. Though the $\mathrm{N}$-glycan release assay showed high precision, the normal-phase method used for the assay could not fully resolve all the glycoforms. Collectively, the results suggest that MS quantitation based on analysis of $\mathrm{Fc} / 2$ (reduced $\mathrm{Fc}_{\mathrm{c}}$ ) is accurate and gives results that are both comparable and complementary to the more timeconsuming $\mathrm{N}$-glycan release assay.

\section{References}

1. Zhang, J.; Wang, D. I. Quantitative Analysis and Process Monitoring of Site-Specific Glycosylation Microheterogeneity in Recombinant Human Interferon- $\gamma$ from Chinese Hamster Ovary Cell Culture by Hydrophilic Interaction Chromatography. J. Chromatogr. B Biomed. Sci. Appl. 1998, 712, 73-82.

2. Kunkel, J. P.; Jan, D. C.; Butler, M.; Jamieson, J. C. Comparisons of the Glycosylation of a Monoclonal Antibody Produced Under Nominally Identical Cell Culture Conditions in Two Different Bioreactors. Biotechnol. Prog. 2000, 16, 462-470.

3. Delorme, E.; Lorenzini, T.; Giffin, J.; Martin, F.; Jacobsen, F.; Boone, T.; Elliott, S. Role of Glycosylation on the Secretion and Biological Activity of Erythropoietin. Biochemistry 1992, 31, 9871-9876.
4. Keusch, J.; Lydyard, P. M.; Delves, P. J. The Effect on IgG Glycosylation of Altering $\beta 1$, 4-galactosyltransferase-1 activity in B cells. Glycobiology $1998,8,1215-1220$.

5. Tagashira, M.; Iijima, H.; Isogai, Y.; Hori, M.; Takamatsu, S.; Fujibayashi, Y.; Yoshizawa-Kumagaya, K.; Isaka, S.; Nakajima, K.; Yamamoto, T.; Teshima, T.; Toma, K. Site-Dependent Effect of O-Glycosylation on the Conformation and Biological Activity of Calcitonin. Biochemistry 2001, 40, 11090-11095.

6. Jefferis, R. Antibody Therapeutics: Isotype and Glycoform Selection. Expert Opin. Biol. Ther. 2007, 7, 1401-1413.

7. Edelman, G. M.; Cunningham, B. A.; Gall, W. E.; Gottlieb, P. D. Rutishauser, U.; Waxdal, M. J. The Covalent Structure of an Entire $\gamma-\mathrm{G}$ Immunoglobulin Molecule. 1969. J. Immunol. 2004, 173, 5335-5342.

8. Mimura, Y.; Church, S.; Ghirlando, R.; Ashton, P. R.; Dong, S.; Goodall, M.; Lund, J.; Jefferis, R. The Influence of Glycosylation on the Thermal Stability and Effector Function Expression of Human IgG1-Fc: Properties of a Series of Truncated Glycoforms. Mol. Immunol. 2000, 37, 697-706.

9. Krapp, S.; Mimura, Y.; Jefferis, R.; Huber, R.; Sondermann, P. Structural Analysis of Human IgG-Fc Glycoforms Reveals a Correlation Between Glycosylation and Structural Integrity. J. Mol. Biol. 2003, 325, 979-989.

10. Masuda, K.; Yamaguchi, Y.; Kato, K.; Takahashi, N.; Shimada, I.; Arata, Y. Pairing of Oligosaccharides in the Fc Region of Immunoglobulin G. FEBS Lett. 2000, 473, 349-357.

11. Wuhrer, M.; Deelder, A. M.; Hokke, C. H. Protein Glycosylation Analysis by Liquid Chromatography-Mass Spectrometry. 18. J. Chromatogr. B Analyt. Technol. Biomed. Life Sci. 2005, 825, 124-133.

12. Gadgil, H. S.; Bondarenko, P. V.; Pipes, G. D.; Dillon, T. M.; Banks, D.; Abel, J.; Kleemann, G. R.; Treuheit, M. J. Identification of Cysteinylation of a Free Cysteine in the Fab Region of a Recombinant Monoclonal IgG1 Antibody Using Lys-C Limited Proteolysis Coupled with LC/MS Analysis. Anal. Biochem. 2006, 355, 165-174.

13. Gadgil, H. S.; Pipes, G. D.; Dillon, T. M.; Treuheit, M. J.; Bondarenko, P. V. Improving Mass Accuracy of High Performance Liquid Chromatography/Electrospray Ionization Time-of-Flight Mass Spectrometry of Intact Antibodies. J. Am. Soc. Mass Spectrom. 2006, 17, $867-872$.

14. Gadgil, H. S.; Bondarenko, P. V.; Pipes, G.; Rehder, D.; McAuley, A.; Perico, N.; Dillon, T.; Ricci, M.; Treuheit, M. The LC/MS Analysis of Glycation of IgG Molecules in Sucrose Containing Formulations. J. Pharm. Sci. 2007, 96, 2607-2621.

15. Mimura, Y.; Ashton, P. R. Takahashi, N: Harvey, D. J; Jefferis, R. Contrasting Glycosylation Profiles Between Fab and Fc of a Human IgG Protein Studied by Electrospray Ionization Mass Spectrometry. J. Immunol. Methods 2007, 326, 116-126.

16. Hills, A. E.; Patel, A.; Boyd, P.; James, D. C. Metabolic Control of Recombinant Monoclonal Antibody N-Glycosylation in GS-NS0 Cells. Biotechnol. Bioeng. 2001, 75, 239-251.

17. Ren, D.; Pipes, G.; Xiao, G.; Kleemann, G.R.; Bondarenko, P. V.; Treuheit, M. J.; Gadgil, H. S. Reversed-Phase Liquid ChromatographyMass Spectrometry of Site-Specific Chemical Modifications in Intact Immunoglobulin Molecules and Their Fragments. J. Chromatogr. A 2007, 1179, 198-204

18. Ren, D.; Pipes, G. D.; Hambly, D. M.; Bondarenko, P. V.; Treuheit, M. J.; Brems, D. N.; Gadgil, H. S. Reversed-Phase Liquid Chromatography of Immunoglobulin G Molecules and Their Fragments with the Diphenyl Column. J. Chromatogr. A 2007, 1175, 63-68.

19. Masuda, K.; Yamaguchi, Y.; Kato, K.; Takahashi, N.; Shimada, I.; Arata, Y. Pairing of Oligosaccharides in the Fc Region of Immunoglobulin G. FEBS Lett. 2000, 473, 349-357.

20. Boushaba, R.; Kumpalume, P.; Slater, N. K. Kinetics of Whole Serum and Prepurified IgG Digestion by Pepsin for $\mathrm{F}\left(\mathrm{ab}^{\prime}\right) 2$ Manufacture. Biotechnol. Prog. 2003, 19, 1176-1182.

21. Leslie, R. G.; Melamed, M. D.; Cohen, S. The Products from Papain and Pepsin Hydrolyses of Guinea Pig Immunoglobulins $\gamma-1 \mathrm{G}$ and $\gamma-2 \mathrm{G}$. Biochem. J. 1971, 121, 829-837.

22. Bongers, J.; Cummings, J. J.; Ebert, M. B.; Federici, M. M.; Gledhill, L. Gulati, D.; Hilliard, G. M.; Jones, B. H.; Lee, K. R.; Mozdzanowski, J.; Naimoli, M.; Burman, S. Validation of a Peptide Mapping Method for a Therapeutic Monoclonal Antibody: What Could We Possibly Learn About a Method We Have Run 100 Times? J. Pharm. Biomed. Anal. 2000, 21, 1099-1128.

23. Hills, A. E.; Patel, A.; Boyd, P.; James, D. C. Metabolic Control of Recombinant Monoclonal Antibody N-Glycosylation in GS-NS0 Cells. Biotechnol. Bioeng. 2001, 75, 239-251.

24. Bykova, N. V.; Rampitsch, C.; Krokhin, O.; Standing, K. G.; Ens, W. Determination and Characterization of Site-Specific N-Glycosylation Using MALDI-Qq-TOF Tandem Mass Spectrometry: Case Study with a Plant Protease. Anal. Chem. 2006, 78, 1093-1103.

25. Mirgorodskaya, E.; Krogh, T. N.; Roepstorff, P. Characterization of Protein Glycosylation by MALDI-TOFMS. Methods Mol. Biol. 2000, 146, 273-292. 